\title{
University Students' Perceptions of the Use of Digital Technologies in their Formal Learning: A Developing Country Perspective
}

\author{
Al-Mothana M. Gasaymeh \\ Curriculum and Instruction Department \\ Al-Hussein Bin Talal University \\ Ma'an, Jordan \\ E-mail: gasaymeh@gmail.com \\ Adnan M. Al-Taweel \\ Curriculum and Instruction Department \\ Al-Hussein Bin Talal University \\ Ma'an, Jordan \\ Khaldun G. Al-Moghrabi \\ College of Information Technology \\ Al-Hussein Bin Talal University \\ Ma'an, Jordan \\ Ali M. Al-Ghonmein \\ College of Information Technology \\ Al-Hussein Bin Talal University \\ Ma'an, Jordan
}

Received: August 9, 2017 Accepted: August 29, 2017 Published: August 31, 2017

doi:10.5296/ijld.v7i3.11666

URL: https://doi.org/10.5296/ijld.v7i3.11666 


\title{
Macrothink
}

\begin{abstract}
The purpose of this study was twofold: (1) to examine university students' perceptions of the use digital technologies in their formal learning, and (2) to examine differences in the their perceptions of the use of digital technologies in their formal learning, based on their gender, age, major, academic year, perceptions of digital competence, and perceptions of digital dependence. A descriptive survey research method was used; a questionnaire was used to collect data. The participants were students enrolled in different classes in the second semester in the academic year of 2016/2017 at a university in Jordan. The results showed that the participants had positive perceptions of the use digital technologies in their formal learning in affective, cognitive, and conative domains. Students' perceptions of the use digital technologies in their formal learning did not differ significantly according to gender, age, major, or perceived digital dependency. However, students' perceptions of the use digital technologies in their formal learning were influenced by their academic year and perceived digital competency. Recommendations based on the findings were presented.
\end{abstract}

Keywords: students' perceptions, digital technologies, formal learning, digital competence, digital dependence, gender, age, major, university students, developing countries 


\section{Introduction}

Creating a knowledge-based economy has become the goal of many developing countries, especially those that suffer from a scarcity of natural resources. The creation of knowledge-based economies in developing countries involves the development of their higher education systems. The integration of digital technologies into the higher education systems of these countries has the potential to contribute in their development and restructuring. For instance, Kozma (2005) stated that "Information and communication technology (ICT) is a principal driver of economic development and social change, worldwide. In many countries, the need for economic and social development is used to justify investments in educational reform and in educational ICT” (p. 117).

In addition to the role of digital technologies in the reformation of higher education, and in the creation of knowledge-based economies in developing countries, the integration of these technologies in higher education has direct benefits for universities, faculty members, and students. Universities that facilitate the use of digital technologies for administrative and educational purposes are likely to: attract more students; solve the problem of a shortage of qualified staff; increase staff satisfaction/motivation; develop staff skills; improve organizational efficiency; enhance the public profile of the institution; build strategic partnering with external organizations; and increase income (Nicol \& Coen, 2003).

For faculty members, the integration of digital technologies in their teaching practice has the potential to: improve their teaching practice; increase their efficiency and productivity; and improve their connections to their students (Ransom, Graham, \& Mott, 2007). For students, the integration of simple and sophisticated digital technologies in their education has the potential to: empower them through enhancing their learning; increase their motivation; build their self-confidence in learning; promote collaborative learning; promote active learning; provide them with different types of educational resources; promote lifelong learning; and make them self-regulated learners (Valk, Rashid, \& Elder, 2010; Gasaymeh \& Qablan, 2013; Gasaymeh \& Aldalalah, 2013; Pellas \& Kazanidis, 2014; Tarus, Gichoya, \& Muumbo, 2015)

A few decades ago, the integration of digital technologies in higher education for administrative and educational purposes needed huge investments in infrastructure and technological tools. This meant that developing countries were unable to take advantage of the integration digital technology in higher education for administrative and educational purposes (Balasubramanian et al., 2009). Nowadays, the emergence of new affordable technologies such as smartphones, and the ease of access to significant technologies such as the internet, make it easier for developing countries to take advantage of such technologies and integrate them into their higher education systems. In developing countries, research has shown that university students are heavy users of, and are highly dependent on, different types of technology such as smartphones and smartphones apps (Dahlstrom, Walker, \& Dziuban 2014; Al-Shboul, Al-Saideh, \& Al-Labadi, 2017), social networking sites (SNSs) (Hamade, 2013; Bsharah, Gasaymeh, \& Abdelrahman, 2014; Abu-Alruz, 2014), and the internet (Waycott, Bennett, Kennedy, Dalgarno, \& Gray, 2010). However, their use of such technologies is commonly for personal and social purposes. Therefore, there is a need to 
examine whether students are willing to transfer their use of these technologies to educational purposes.

Students' perceptions of the formal use of different digital technologies for educational purposes have been examined in research. For example, Waycott, Bennett, Kennedy, Dalgarno, and Gray (2010) investigated university students' perceptions of the integration of ICT in their learning. They found that the benefits of the use of ICT in education included "communication benefits, convenience, gaining access to information resources, distance education benefits, and providing opportunities to review and revise learning materials" ( $\mathrm{p}$. 1207). But the authors reported that, the key drawbacks were "access to technology; poor replacement for non-technology mediated learning; usability issues; difficulties learning to use the technology; and 'missed' communication" (p. 1207). In a more recent study, Makura (2014) investigated students' perceptions of the use of ICT in their learning in a university in South Africa. They found that the students believed that the use of ICT would have a positive influence their academic performance and increase their access to educational resources.

Some research has examined students' perceptions of the use of specific types of technologies. For instance, Kim, Rueckert, Kim, and Seo (2013) found that university students had positive perceptions of the use of their mobile devices to support their learning. The students reported that these devices would be useful for their learning because they would increase their access to educational resources and improve their communication with other students and with instructors. In another study that examined students' perceptions of the use of social networking service for educational purposes, Hamid, Waycott, Kurnia, and Chang (2015) found that the students said that the use of social networking would enhance their interactions with each other, with their instructors, and with the educational content.

Other studies have investigated the factors that influence students' perceptions and acceptance of the use of digital technologies in their education. Tagoe (2012) examined the factors that influenced Ghanian university students' perceptions on integrating e-learning in their education. The results showed that the students' acceptance of e-learning was significantly related to computer ownership, and to prior experience and perceptions of e-learning. In Jordan, Al-Adwan, Al-Adwan, and Smedley (2013) employed the Technology Acceptance Model (TAM) to assess university students' acceptance of e-learning. The results showed that perceived usefulness was a significant predictor of students' acceptance of e-learning. Abedalaziz, Jamaluddin, and Chin (2013) examined Malaysian university students' attitudes toward the use of computers and the internet. They found that participants had a highly positive perception of the usefulness of these tools. Students' perceptions did not differ based on their gender and field of study. However, young students had higher positive perceptions of computers and the internet than older ones. In Libya, Rhema and Miliszewska (2014) examined engineering students' attitudes toward the use of ICT in their learning. They found that the students had confidence in using computers; they enjoyed using a range of ICTs in their education, they believed in the usefulness of e-learning, and they responded positively to the use of e-learning in their education. Students' attitudes toward the use of ICT in their learning did not differ based on their gender, age, or academic year. However, students' attitudes toward the use of ICT in their learning differed based on their levels of 


\section{Macrothink}

digital skills. In another study, Kitchakarn (2015) examined university students' attitudes toward using computer as a learning tool in a higher education institution in Thailand and their relations with some students' demographic characteristics and their use of computers. The results showed that students had positive attitudes toward using computers for educational purposes. Their attitudes did not differ based on their gender and computer experience, but they did differ based on their ability to use computer programs. Wong, Tan, Loke, and Ooi (2015) examined the factors that influence users' intentions to use mobile SMS to facilitate their learning; they found that performance expectancy, effort expectancy, learning compatibility, reachability, and convenience all had significant influences on intentions to use. In a more recent study, Baturay, Gökçearslan, and Ke (2017) examined the factors that influence students' intentions of accepting technology. The results showed that computer knowledge and skills and attitudes towards the use of computer in education had significant and positive relationships with students' intentions to accept technology.

The above studies show that university students in different countries have positive perceptions of the use of different types of digital technologies in their learning and teaching. However, such perceptions are influenced by different factors in different countries. In Jordan, university students commonly use a range of digital technologies in their personal and social lives. Therefore, there is a need to examine whether the students are willing to transfer this use to serve educational purposes, and to examine the factors that might influence their perceptions.

\section{Purpose of the Study}

The purpose of this study was twofold: (1) to examine university students' perceptions of the use digital technologies in their formal learning, and (2) to examine differences in the their perceptions of the use of digital technologies in their formal learning, based on their gender, age, major, academic year, perceived digital competency, and perceived digital dependency.

The research questions of the current study were:

1) What are students' perceptions of the use of digital technologies in their formal learning?

2) What are the relationships between students' perceptions of the use of digital technologies in their formal learning and their:

•gender

•major

-academic year

-perceived digital competency

-perceived digital dependency?

\section{Research Method}

A quantitative approach was used. A cross-sectional survey was used in which a group of students from a university in Jordan participated. The following sub-sections present the data 
collection instrument and procedure; the data analysis procedure; and descriptions of the participants.

\subsection{Data Collection Instrument and Procedure}

The data collection instrument used was a questionnaire. The questionnaire consisted of two sections. The first section consisted of questions related to participants' characteristics and perceptions of their digital competence and digital dependence. Digital dependence refers to the degree of relying on digital devices.

The second section consisted of questions related to students' perceptions of the formal integration of digital technologies in their learning. The options for responses to the questions related to digital competence and digital dependence were: low, medium, and high. The options for responses to the questions related to students' perceptions of the formal integration of digital technologies in their learning were on a five-point Likert scale. They included strongly disagree, disagree, undecided, agree, and strongly agree. The researcher developed the research instrument based on the reviewed literature. The validity and reliability of the instrument was checked through feedback from a panel of experts and the use Cronbach's Alpha. The Cronbach's Alpha for the perception section was 9, reflecting excellent reliability of the instrument. To describe students' responses to the perception questions, descriptive levels of the mean scores of the items were adopted (Table 1).

Table 1. Descriptive Levels of the Mean Scores

\begin{tabular}{ll}
\hline Level & Mean scores \\
\hline Very low & 0.0 to 1.49 \\
Low & 1.5 to 2.49 \\
Moderate & 2.5 to 3.49 \\
High & 3.5 to 4.49 \\
Very high & 4.5 to 5 \\
\hline
\end{tabular}

The procedure used to collect data started with contacting several faculty members to obtain their permission to distribute the questionnaire in their classes. Five faculty members agreed to have their students participate. The researcher visited each class and delivered a presentation regarding the use of digital technologies in formal learning. Then, after informing the students about the purpose of the study, they were invited to participate. The questionnaires were handed to the students. The students who agreed to participate completed the questionnaires and returned them at the same lesson.

\subsection{Data Analysis}

The data analysis started with the descriptive statistics that involved calculating the frequency distributions of the data related to the participants' demographic information, their perceived digital competency, and their perceived digital dependency. Means and standard deviations 
were used to convey students' perceptions of the use of digital technologies in their formal learning. Independent sample t-tests and analysis of variance (ANOVA) tests were used to examine the differences in students' perceptions of the use of digital technologies in their formal learning based on gender, major, academic year, perceived digital competency, and perceived digital dependency.

\subsection{Participants}

The participants were students in a university in Jordan who were registered in the second semester of the academic year of 2016/2017. The questionnaire collected data on their gender, age, major, and academic year. In addition, the questionnaire instrument collected data regarding their perceptions of their digital competency and digital dependency (Table 2).

Table 2. Descriptive Summary of Participants' Demographic Data and Perceived ICT Competency and Dependency $\mathrm{N}=218$

\begin{tabular}{|c|c|c|c|}
\hline & Category & Frequency & Percent \\
\hline \multirow[t]{2}{*}{ Gender } & Male & 76 & \multirow{2}{*}{$\begin{array}{l}34.9 \\
65.1\end{array}$} \\
\hline & Female & 142 & \\
\hline \multirow[t]{3}{*}{ Age } & $18-20$ & 143 & 65.6 \\
\hline & $20-25$ & 71 & 32.6 \\
\hline & $26-30$ & 2 & 0.9 \\
\hline \multirow[t]{6}{*}{ Major } & Education & 38 & 17.4 \\
\hline & Arts and Literatures & 48 & 22.0 \\
\hline & Science & 48 & 22.0 \\
\hline & Engineering and Computer Science & 27 & 12.4 \\
\hline & Nursing and Health Science & 36 & 16.5 \\
\hline & Business Management & 21 & 9.6 \\
\hline \multirow[t]{5}{*}{ Academic year } & 1 & 140 & 64.2 \\
\hline & 2 & 10 & 4.6 \\
\hline & 3 & 22 & 10.1 \\
\hline & 4 & 40 & 18.3 \\
\hline & 5 & 6 & 2.8 \\
\hline \multirow[t]{3}{*}{ Perceived digital competency } & Low & 4 & 1.8 \\
\hline & Medium & 75 & 34.4 \\
\hline & High & 139 & 63.8 \\
\hline \multirow[t]{3}{*}{ Perceived digital dependency } & Low & 0 & 0.0 \\
\hline & Medium & 56 & 25.7 \\
\hline & High & 162 & 74.3 \\
\hline
\end{tabular}




\section{Macrothink}

International Journal of Learning and Development

ISSN 2164-4063

2017, Vol. 7, No. 3

The number of female students was about twice the number of male students. The number of the students who were less than 20 years old was about twice the number of students who were between the ages of 20 and 25 . Two participants were older than 25 . The students were from different departments in different academic years. Such variations in students' ages, majors, and academic years were due to the types of classes that participated in the study. The classes were electives in which students from different departments could enroll. Some of these classes were offered for first year students. Most of the participants believed that they possessed high levels of digital competency and high level of digital dependency. No participants believed that they had low levels of digital dependency (Table 2). These findings suggest that the participants were familiar with common digital technologies and were highly dependent on them in their daily lives.

\section{Results and Discussion}

\subsection{Students'Perceptions of the Use Digital Technologies in their Formal Learning}

The results suggest that the participants had positive perceptions of the use of digital technologies in their formal learning. Participants' perceptions of the use of digital technologies in their formal learning are presented in Table 3.

Table 3. Descriptive Statistics of Participants' Responses to the Perceptions of the Use Digital Technologies in their Formal Learning Scale $(N=218)$

\begin{tabular}{|c|c|c|c|}
\hline & Perceptions scale & $\mathrm{M}$ & SD \\
\hline 1 & I believe that the use of digital technologies in my formal education is a good idea & 4.24 & 0.96 \\
\hline 2 & I like to use digital technologies in my formal education & 4.13 & .94 \\
\hline 3 & $\begin{array}{l}\text { The use of digital technologies in my formal education will provide me with a lot of } \\
\text { enjoyment. }\end{array}$ & 4.07 & 1.03 \\
\hline 4 & If it becomes available I would like to use digital technologies in my formal education & 3.99 & 1.00 \\
\hline 5 & $\begin{array}{l}\text { The use of digital technologies in my formal education helps me organize my learning } \\
\text { better }\end{array}$ & 3.93 & 0.99 \\
\hline 6 & $\begin{array}{l}\text { I do not feel scared and hesitant when using digital technologies in my formal } \\
\text { education }\end{array}$ & 3.98 & 1.08 \\
\hline 7 & If I have problems using digital technologies in my education I can solve them & 3.79 & 1.00 \\
\hline 8 & $\begin{array}{l}\text { I will use digital technologies in my education frequently during my undergraduate } \\
\text { studies }\end{array}$ & 3.87 & 1.01 \\
\hline 9 & $\begin{array}{l}\text { The use of digital technologies in my education would increase my productivity in my } \\
\text { coursework. }\end{array}$ & 3.90 & 1.00 \\
\hline \multirow[t]{2}{*}{10} & Overall, I would like to use digital technologies in my formal education & 3.96 & 1.03 \\
\hline & Overall & 3.99 & 0.72 \\
\hline
\end{tabular}

Participants' overall perceptions of the use of digital technologies in their formal learning 
were highly positive $(M=3.99, S D=0.72)$. Participants responded most positively to the item that stated "I believe that the use of digital technologies in my formal education is a good idea" $(M=4.24, S D=0.96)$, and least positively to the item that stated "I would like to use digital technologies in my formal education" $(M=3.96, S D=1.03)$. The mean scores for all items were high. In the affective domain, the students expressed positive feelings regarding the use of digital technologies in their formal learning. In the cognitive domain, they believed that the use of digital technologies in their formal learning would be useful, enjoyable, helpful for organizing their learning, easy to use, and would increase their educational productivity. In the conative domain, the students said they would use ICT in their formal learning. The students formed their perceptions of the use of digital technologies in their formal learning based on their experiences of the use of such technologies in their personal and social lives as well as the use of these technologies in informal learning. The findings aligned with findings of similar studies that showed students had positive perceptions about the use of digital technologies in their formal learning, examples of these digital technologies include mobile devices (Kim, et al, 2013); mobile SMS (Wong, et al, 2015), online social networking (Hamid, et al, 2015) and general ICT (Waycott et al, 2010; Makura 2014). The findings suggest that students would accept the use of digital technologies in their formal learning. Institutions of higher education should take advantage of these attitudes by integrating digital technologies into formal educational processes.

\subsection{Gender and Students' Perceptions of the Use Digital Technologies in their Formal Learning}

Participants' responses to the perceptions scale were compared based on their gender through the use of independent sample t-tests (Table 4).

Table 4. Results of T-Tests and Descriptive Statistics of Students' Perceptions of the Use Digital Technologies in their Formal Learning by Gender

\begin{tabular}{|c|c|c|c|c|c|c|c|c|c|}
\hline \multirow{3}{*}{ Outcome } & \multicolumn{6}{|c|}{ Group } & \multirow{3}{*}{$t$} & \multirow{3}{*}{$d f$} & \multirow{3}{*}{$p$} \\
\hline & \multicolumn{3}{|l|}{ Male } & \multicolumn{3}{|c|}{ Female } & & & \\
\hline & $M$ & $S D$ & $n$ & $M$ & $S D$ & $n$ & & & \\
\hline Perceptions & 4.05 & 0.83 & 76 & 4.00 & 0.66 & 142 & -9.54 & 216 & 0.34 \\
\hline
\end{tabular}

There were insignificant variations between female and male students in their perceptions of the use digital technologies in their formal learning. This finding is consistent with similar studies. For instance, Kitchakarn (2015) found that students' attitudes toward using computers as a learning tool did not differ based on their gender. Rhema and Miliszewska (2014) found that engineering students' attitudes toward the use of ICT in their learning did not differ based on gender. The findings suggest that the use of digital technologies for educational purposes would be equally acceptable for female and male students. 
4.3 Age and Students' Perceptions of the Use Digital Technologies in their Formal Learning

Participants' responses to the perception scales were compared based on their age through the use of a one-way ANOVA test (Table 5).

Table 5. One-Way ANOVA- Students' Responses to the Perceptions of the Use Digital Technologies in their Formal Learning scale for Age

\begin{tabular}{lccc}
\hline Outcome & $d f$ & $F$ & $p$ \\
\hline Perceptions & 2 & 1.32 & 0.271 \\
\hline
\end{tabular}

The results showed that students' perceptions of the use digital technologies in their formal learning did not differ based on their age. A possible explanation is that there were small variations in students' ages, and the great majority of them were between the ages of 18 and 25. Based on Prensky's (2001) definition, all the students in the current study were "digital natives" since they were born after 1980. Digital natives have developed skills in using digital technologies and they have developed new cognitive capacities related to the use of digital technologies. These findings are consistent with Rhema and Miliszewska's (2014) study, which found that students' attitudes toward the use of ICT in their learning did not differ based on their age. Contrary to these findings, Abedalaziz et al (2013) reported a significant relationship between students' ages and their attitudes toward ICT. However, Abedalaziz, et al (2013) reported a wide age gap among participants. The findings suggest that most university students aged between 18 and 25 would accept the use of digital technologies in their learning.

\subsection{Major and Students' Perceptions of the Use Digital Technologies in their Formal Learning}

Participants' responses on the perception scale were compared based on their major through the use of a one-way ANOVA test (Table 6).

Table 6. One-Way ANOVA- students' Responses to the Perceptions of the Use Digital Technologies in their Formal Learning scale for Major

\begin{tabular}{lccc}
\hline Outcome & $d f$ & $F$ & $p$ \\
\hline perceptions & 5 & 0.456 & 0.809 \\
\hline
\end{tabular}

The results showed that students' perceptions of the use digital technologies in their formal learning did not differ based on their major. A possible explanation is that common digital technologies such as smartphones and smartphones apps are popular among all the students 
regardless of their major. This popularity makes students from different disciplines form positive perceptions of the use of digital technologies in their formal learning. These findings are consistent with Abedalaziz et al. (2013) who found that students' perceptions of computer and internet use did not differ based on their major. The findings suggest that the use of digital technologies for educational purposes would be equally acceptable for university students in different academic disciplines.

\subsection{Academic Year and Students' Perceptions of the Use Digital Technologies in their Formal Learning}

Participants' responses on the perception scale were compared based on their academic year through the use of a one-way ANOVA test (Table 7).

Table 7. One-Way ANOVA- Students' Responses to the Perceptions of the Use Digital Technologies in their Formal Learning scale for Academic year

\begin{tabular}{lccc}
\hline Outcome & $d f$ & $F$ & $p$ \\
\hline Perceptions & 4 & 1.42 & 0.03 \\
\hline
\end{tabular}

The results showed that students' perceptions of the use digital technologies in their formal learning differed based on their academic year. A post hoc pairwise comparison of the means of responses to the use digital technologies in formal learning was conducted. Significant differences were found between the students in their first, third and fourth academic years. Participants in the fourth academic year had higher positive perceptions of the use of digital technologies in their formal learning $(M=4.25, S D=0.45)$ than the students in their third academic year $(M=3.65, S D=.79 ; p<.05)$ and the students in first academic year $(M=3.98$, $S D=.76 ; p<0.05)$. A possible explanation is that university students in their fourth academic year might have used and benefited from digital technologies in their formal and informal learning more than students in their earlier academic years, and that this made them form more positive perceptions of the use of ICT in their formal learning. Contrary to these findings, Rhema and Miliszewska (2014) reported no significant relation between students' academic years and their attitudes toward the use of ICT in their learning. The findings suggest that the use of ICT would be more acceptable among students in their final academic years than among students in their earlier academic years.

4.6 Perceived Digital Competency and Students' Perceptions of the Use Digital Technologies in their Formal Learning

Participants' responses to the perceptions scales were compared based on their perceptions of their levels of digital competency through the use of a one-way ANOVA test (Table 8). 
Table 8. One-Way ANOVA- Students' Responses to the Perceptions of the Use Digital Technologies in their Formal Learning scale for Perceived Digital Competency

\begin{tabular}{lccc}
\hline Outcome & $d f$ & $F$ & $p$ \\
\hline Perceptions & 2 & 5.59 & 0.004 \\
\hline
\end{tabular}

The results showed that students' perceptions of the use digital technologies in their formal learning differed based on their perceptions of their level of digital competency. The post hoc pairwise comparison looked at the means of responses to the use digital technologies in formal learning. Significant differences were found between students who perceived that they had high levels of digital competency and those who perceived that they had low or moderate levels. Participants who perceived that they had high levels of digital competency had more positive perceptions of the use digital technologies in their formal learning $(M=4.09, S D=$ $0.62)$ than the participants who perceived that they had moderate level of digital competency $(M=3.84, S D=.79 ; p<0.05)$ and the participants who perceived that they had low level of digital competency $(M=3.18, S D=1.63 ; p<0.05)$. It was expected that students with high digital competence would have positive perceptions and intentions regarding the use digital technologies in their formal learning, since their competence would make the use of digital technologies easy for them. Past studies have shown that the perceived ease of use of a technology can positively influence individual perceptions and use of that technology (Davis, 1986). These findings are consistent with Rhema and Miliszewska (2014) who found that students' attitudes toward the use of ICT in their learning did differ based on their levels of digital skill. The findings suggest that the use of ICT for educational purposes should be accompanied by training in how to use technologies in order to improve students' perceptions of their use.

\subsection{Perceived Digital Dependency and Students'Perceptions of the Use Digital Technologies in their Formal Learning}

Participants' responses to the perception scales were compared based on their perceptions of their levels of digital dependency through the use of an independent sample t-test since the all the participants believed that they had either medium or high levels of digital dependency (Table 9).

Table 9. Results of t-tests and Descriptive Statistics of Students' Perceptions of the Use Digital Technologies in their Formal Learning by Perceived Digital Dependency.

\begin{tabular}{|c|c|c|c|c|c|c|c|c|c|}
\hline \multirow{3}{*}{ Outcome } & \multicolumn{6}{|c|}{ Group } & \multirow{3}{*}{$t$} & \multirow{3}{*}{$d f$} & \multirow{3}{*}{$p$} \\
\hline & \multicolumn{3}{|c|}{ Medium } & \multicolumn{3}{|l|}{ High } & & & \\
\hline & $M$ & $S D$ & $n$ & $M$ & $S D$ & $n$ & & & \\
\hline Perceptions & 3.83 & 0.81 & 56 & 4.04 & 0.68 & 162 & $-1.95^{*}$ & 216 & .052 \\
\hline
\end{tabular}




\section{MInstitute ${ }^{\text {Mnk }}$}

The results showed that there were insignificant variations between students' perceptions of the use digital technologies in their formal learning based on their perceived digital dependency. A possible explanation is that students' digital dependency was related to performing routine and simple tasks such making phone calls and exchanging texts. Therefore, their perceived digital dependency did not significantly influence their perceptions of the use of digital technologies for more sophisticated and formal educational tasks. In addition, there was not a wide gap between the levels of perceived digital dependency among students, since none of the participants reported having a low level of digital dependency. The findings suggest that the use of digital technologies for educational purposes would be acceptable for the students who are highly or moderately dependent on digital technologies in their personal and social lives.

\section{Conclusion, Limitations, and Recommendations}

Previous research has shown that digital technologies have several benefits for higher educational systems and the stakeholders involved (i.e. students, instructors, and administrators). In addition, research has shown that ICT is widespread amongst university students, and they commonly use different types of digital technologies in their personal and social lives. The benefits and popularity of digital technologies among university students suggest that higher education institutions should integrate such technologies for educational and administrative purposes. Therefore, there is a need to examine whether the students are willing to transfer their use of these technologies for personal and social purposes to serve educational purposes, and to examine the factors that might influence their perceptions.

The current study found that participants perceived themselves as having high digital competency and high digital dependency. They had positive perceptions of the use of digital technologies in their formal learning in affective, cognitive, and conative domains. They liked the idea of using digital technologies in their formal education and did not feel anxious or hesitant about such use. They believed that digital technologies would be easy to use and would increase their productivity, enhance their organization for learning, and provide enjoyment. The students intended to use these digital technologies when they became formally integrated into their learning. Students' perceptions of the use digital technologies in their formal learning were not significantly different based on their gender, age, major, and perceived digital dependency. However, students' perceptions of the use digital technologies in their formal learning were influenced by their academic year and perceived digital competency. Students in their fourth academic year had higher positive perceptions of the use of digital technologies in their formal learning than students in their earlier academic years. The students who perceived themselves to have high levels of digital competency had higher positive perceptions of the use of digital technologies in their formal learning than the students who perceived themselves to have low and moderate levels of digital competency.

It would be useful to conduct a comparison of perceptions of the use of digital technologies in formal learning between students in different cultures and countries. In Jordan, institutions of higher education and educational authorities may benefit from the findings of the current study regarding students' perceptions of the use of digital technologies in their formal 
learning and the factors that may influence such perceptions. The findings suggest that university students will accept of the use of digital technologies in their formal learning. Considering the benefits of the integration of digital technologies in students learning and students' acceptance of such integration, institutions of higher education should integrate digital technologies to support students' learning and teaching. The findings suggest that the most suitable types of technologies would be the ones that the students already use in their daily lives. Students' perceptions of the use of digital technologies in their formal learning will influence their actual use of such technologies. Therefore, institutions of higher education should enhance students' perceptions of the use of digital technologies in their formal education through the use of appropriate interventions such as seminars and training programs. The interventions used should be independent of gender, age, and major, but should take account of which academic year the students are in.

Future research could build on the current study by examining other factors that might influence students' perceptions of the use of digital technologies in their formal learning. Being aware of key factors of students' acceptance of the use of technologies in their learning would help in guiding the process of designing and introducing different types of digital technology into students' formal learning. Future research could examine students' perceptions of the use of specific digital technologies in their formal learning. In addition, similar research might be conducted in different settings, with different participants, and research methods to achieve an enhanced understanding of students' perceptions of the use of digital technologies.

The current study has some limitations related to the data since it was collected through self-reports. In addition, the sample size was not large and the sample was not representative of all the universities in Jordan, and that limits its generalizability. The data was collected at one time, while perceptions change over time. Therefore, the stability of students' perceptions was not established. Furthermore, a limited number of factors were examined to gauge their impact on students' perceptions of the use of digital technologies in their formal learning.

\section{References}

Abedalaziz, N., Jamaluddin, S., \& Chin, H. L. (2013). Measuring attitudes toward computer and internet usage among postgraduate students in Malaysia. TOJET: The Turkish Online Journal of Educational Technology, 12(2).

Abu-Alruz, J. (2014). Facebook Use in Education: experiences of university science education students in Jordan. E-Learning and Digital Media, 11(3), 291-299. https://doi.org/10.2304/elea.2014.11.3.291

Al-Adwan, A., Al-Adwan, A., \& Smedley, J. (2013). Exploring students acceptance of e-learning using Technology Acceptance Model in Jordanian universities. International Journal of Education and Development using Information and Communication Technology, $9(2), 4$.

Al-Shboul, M., Al-Saideh, M., \& Al-Labadi, N. (2017). Learners' perspectives of using ICT in higher education institutions in Jordan. International Journal of Instructional Technology 
and Distance Learning, 14(3), 27-86

Balasubramanian, K., Clarke-Okah, W., Daniel, J., Ferreira, F., Kanwar, A., Kwan, A., Lesperance, J., Mallet, J., Umar, A., \& West. P. (2009). ICTs for Higher Education: Background paper from the Commonwealth of Learning. Paper presented for the UNESCO World Conference on Higher Education. Paris, France. Retrieved from http://unesdoc.unesco.org/images/0018/001832/183207e.pdf

Baturay, M. H., Gökçearslan, Ş., \& Ke, F. (2017). The relationship among pre-service teachers' computer competence, attitude towards computer-assisted education, and intention of technology acceptance. International Journal of Technology Enhanced Learning, 9(1), 1-13. https://doi.org/10.1504/ijtel.2017.084084

Bsharah, M., Gasaymeh, A. M., \& Abdelrahman, M. B. (2014). The Relationship between the Use of Social Networking Sites (SNS) and Perceived Level of Social Intelligence among Jordanian University Students: The Case of Facebook. International Journal of Psychological Studies, 6(3), 1. https://doi.org/10.5539/ijps.v6n3p1

Dahlstrom, E., Walker, J. D., \& Dziuban, C. (2012). ECAR study of undergraduate students and information technology. Retrieved from http://www.educause.edu/ecar.

Davis, F. (1986). A technology acceptance model for empirically testing new end-user information systems: theory and results (Unpublished Doctoral dissertation), MIT Sloan School of Management, Cambridge, MA.

Gasaymeh, A. M. M., \& Aldalalah, O. M. (2013). The Impact of Using SMS as Learning Support Tool on Students' Learning. International Education Studies, 6(10), 112-123. https://doi.org/10.5539/ies.v6n10p112

Gasaymeh, A. M. M., \& Qablan, B. M. (2013). SMS as Out-of-Class, Student-Instructor Interaction Tool: A Case Study of Jordanian Graduate Students' Perceptions and Usage. International Education Studies, 6(8), 147. https://doi.org/10.5539/ies.v6n8p147

Hamade, S. N. (2013). Perception and use of social networking sites among university students. Library Review, 62(6/7), 388-397. https://doi.org/10.1109/itng.2013.67

Hamid, S., Waycott, J., Kurnia, S., \& Chang, S. (2015). Understanding students' perceptions of the benefits of online social networking use for teaching and learning. The Internet and Higher Education, 26, 1-9. https://doi.org/10.1016/j.iheduc.2015.02.004

Kim, D., Rueckert, D., Kim, D. J., \& Seo, D. (2013). Students' perceptions and experiences of mobile learning. Language Learning \& Technology. 17(3), 52-73

Kitchakarn, O. (2015). EFL learners' attitudes towards using computers as a learning tool in language learning. TOJET: The Turkish online journal of educational technology, 14(2).

Kozma, R. B. (2005). National policies that connect ICT-based education reform to economic and social development. Human Technology: An interdisciplinary journal on humans in ICT environments, 1 (2), 117-156. https://doi.org/10.17011/ht/urn.2005355 
Makura, A. H. (2014). Students' perceptions of the use of ICT in a higher education teaching and learning context: The case of a South African University. Mediterranean Journal of Social Sciences, 5(11), 43. https://doi.org/10.5901/mjss.2014.v5n11p43

Nicol, D., \& Coen, M. (2003). A model for evaluating the institutional costs and benefits of ICT initiatives in teaching and learning in higher education. ALT-J, 11(2), 46-60. https://doi.org/10.3402/rlt.v11i2.11276

Pellas, N., \& Kazanidis, I. (2014). Engaging students in blended and online collaborative courses at university level through Second Life: Comparative perspectives and instructional affordances. New Review of Hypermedia and Multimedia, 20(2), 123-144. https://doi.org/10.1080/13614568.2013.856958

Prensky, M. (2001). Digital natives, digital immigrants: do they really think differently? On the Horizon, 9(6), 1-6. https://doi.org/10.1108/10748120110424843

Ransom, W., Graham, C. R., \& Mott, J. (2007). Faculty perceptions of technology projects. Educause Quarterly, 30(4), 22.

Rhema, A., \& Miliszewska, I. (2014). Analysis of student attitudes towards e-learning: The case of engineering students in Libya. Issues in Informing Science and Information Technology, 11, 169-190.

Tagoe, M. (2012). Students' Perceptions on Incorporating E-Learning into Teaching and Learning at the University of Ghana. International Journal of Education and Development using Information and Communication Technology, 8(1), 91-103.

Tarus, J. K., Gichoya, D., \& Muumbo, A. (2015). Challenges of implementing e-learning in Kenya: A case of Kenyan public universities. The International Review of Research in Open and Distributed Learning, 16(1). https://doi.org/10.19173/irrodl.v16il.1816

Valk, J. H., Rashid, A. T., \& Elder, L. (2010). Using mobile phones to improve educational outcomes: An analysis of evidence from Asia. The International Review of Research in Open and Distributed Learning, 11(1), 117-140. https://doi.org/10.19173/irrodl.v11i1.794

Waycott, J., Bennett, S., Kennedy, G., Dalgarno, B., \& Gray, K. (2010). Digital divides? Student and staff perceptions of information and communication technologies. Computers \& education, 54(4), 1202-1211. https://doi.org/10.1016/j.compedu.2009.11.006

Wong, C. H., Tan, G. W. H., Loke, S. P., \& Ooi, K. B. (2015). Adoption of mobile social networking sites for learning?. Online Information Review, 39(6), 762-778. https://doi.org/10.1108/oir-05-2015-0152

\section{Copyright Disclaimer}

Copyright for this article is retained by the author(s), with first publication rights granted to the journal.

This is an open-access article distributed under the terms and conditions of the Creative Commons Attribution license (http://creativecommons.org/licenses/by/4.0/). 